\title{
Epigenetic modifications in pediatric acute lymphoblastic leukemia
}

\author{
Michael J. Burke ${ }^{1 *}$ and Teena Bhatla ${ }^{2}$ \\ 1 Division of Pediatric Hematology-Oncology, Medical College of Wisconsin, Milwaukee, WI, USA \\ 2 Division of Pediatric Hematology-Oncology, New York University Langone Medical Center, New York, NY, USA
}

Edited by:

Alan Wayne, Children's Hospital Los

Angeles, USA

Reviewed by:

Patrick Brown, Johns Hopkins

University, USA

Weili Sun, University of Southern

California, USA

*Correspondence:

Michael J. Burke, Medical College of Wisconsin, MACC Fund Research Center, 8701 Watertown Plank Road,

Milwaukee, WI 53226, USA

e-mail:mmburke@mcw.edu

\begin{abstract}
Aberrant epigenetic modifications are well-recognized drivers for oncogenesis. Pediatric acute lymphoblastic leukemia (ALL) is no exception and serves as a model toward the significant impact these heritable alterations can have in leukemogenesis. In this brief review, we will focus on the main aspects of epigenetics, which control leukemogenesis in pediatric ALL, mainly DNA methylation, histone modification, and microRNA alterations. As we continue to gain better understanding of the driving mechanisms for pediatric ALL at both diagnosis and relapse, therapeutic interventions directed toward these pathways and mechanisms can be harnessed and introduced into clinical trials for pediatric ALL.
\end{abstract}

Keywords: epigenetics, methylation, histone, pediatric, leukemia, ALL

\section{INTRODUCTION}

Epigenetics is the study of biochemical modifications of chromatin (1) and have been implicated in the pathogenesis of cancer (2). Epigenetic modifications to DNA are not secondary to changes to the nucleotide sequence itself but rather heritable changes affecting the activity of genes and their cellular expression. Examples include DNA methylation, histone modification, and alterations in non-coding microRNAs (miRNAs). Each of these mechanisms can alter how genes are expressed or silenced without modifying the DNA sequence. If these epigenetic modifications lead to silencing of tumor suppressor genes or activation of oncogenes then it is easy to conceptualize how leukemogenesis can occur.

Unlike chromosomal translocations or gene mutations, which are permanent, hypermethylation of gene promoters is a reversible event that could be targeted with therapeutic agents designed to alter aberrant epigenetic events. Incorporating epigenetic modifying agents into the treatment of pediatric ALL is an exciting approach that theoretically could have a significant impact in the treatment of this disease. This would be particularly true for relapse ALL, which is highly hypermethylated (3-5), and accounts for more deaths than any other pediatric disease and remains the fifth most common pediatric cancer overall (6).

In this brief review, we will focus on the three main areas of epigenetics, which have been implicated in the leukemogenesis of pediatric ALL; DNA hypermethylation, histone modification, and microRNA alterations. As we continue to gain better understanding of the driving mechanisms for pediatric ALL at both diagnosis and relapse, therapeutic interventions directed toward these pathways and mechanisms can be harnessed and introduced into clinical trials.

\section{DNA HYPERMETHYLATION}

Gains of DNA methylation tend to occur in the gene promoter region and are one of the most studied epigenetic abnormalities in oncogenesis $(7,8)$. The methylation occurs at cytosine (C) bases located $5^{\prime}$ to guanosine $(\mathrm{G})$ in a $\mathrm{CpG}$ dinucleotide and often in regions rich in repetitive CpGs known as $\mathrm{CpG}$ islands. The methyl groups are transferred to the $\mathrm{CpG}$ dinucleotide via DNA methyltransferases (Dnmt1, Dnmt3a, and Dnmt3b) and serve to transcriptionally silence genes downstream of the methylated promoter. When aberrant methylation occurs in a cancer cell, it typically results in hypermethylation of tumor suppressor genes. This can lead to disruption of key molecular pathways such as apoptosis, DNA repair pathways, cell cycle checkpoints, and cell differentiation as well as result in activation of metastasis/invasion pathways, drug resistance, and proliferation signal transduction (9).

Various groups have used DNA methylation studies to investigate the underlying epigenetic mechanisms in childhood leukemia. In a large cohort of $137 \mathrm{~B}$-lineage and $30 \mathrm{~T}$-lineage pediatric ALL cases, distinct DNA methylation signatures with significant concordant correlation of gene expression were found to be characteristic of various cytogenetic sub-types (10). In fact, a core set of epigenetically deregulated genes, common to all cases, was identified; suggesting their central role in leukemia initiation and maintenance. Likewise, DNA methylation interrogation of 69 pediatric B-ALL and 42 non-leukemic control samples revealed 325 genes hypermethylated and down regulated, and 45 genes hypomethylated and up-regulated across all the samples, irrespective of subtype (11). Furthermore, gene ontology analysis of these epigenetically deregulated genes highlighted the role of genes involved in cell signaling, cellular development, cell survival, and apoptosis. Another study investigating 764 cases of newly diagnosed ALL and 27 cases of relapse, identified 9406 predominantly hypermethylated CpG sites, independent of cytogenetic background, with each cytogenetic subtype displaying a unique set of hyper- and hypomethylated sites (12). These differentially hypermethylated CpG sites were enriched for genes in 
the transcriptional regulatory network such as NANOG, OCT4, $S O X 2$, and REST. These genes are known to be regulated by a polycomb group of proteins and have been identified as targets for hypermethylation in solid tumors (13), leukemia (14), and lymphoma (15).

MLL-rearranged infant leukemia is one specific ALL subtype that has been shown to exhibit distinct promoter hypermethylation (16-19). Stumpel and colleagues identified a distinct DNA methylation pattern dependent on the presence and type of MLL-fusion partner in a cohort of 57 newly diagnosed infant ALL patients (19). In addition, the degree of hypermethylation appeared to correlate with a higher risk of relapse among infants carrying $t(4 ; 11)$ or $t(11 ; 19)$ translocations. In another study of 5 MLL-rearranged infant ALL samples, genes known to be involved in oncogenesis and tumor progression (DAPK1, CCR6, HRK, LIFR, and $F H I T$ ) were differentially methylated suggesting a role in the leukemogenesis of MLL-rearranged ALL (17). As well, four of five genes that were hypermethylated and silenced were able to be re-expressed in vitro when exposed to DNMTi and regain their functional roles, thus pointing to the clinical potential epigenetic therapy may have in the treatment of infant leukemia.

Relapsed ALL is a highly aggressive disease marked predominantly by drug resistance (20). Efforts are currently being undertaken to identify the role of epigenetic mechanisms in driving relapse and chemoresistance (3). Genome-wide DNA methylation profiling performed on 33 matched relapse-diagnosis pairs demonstrated that the relapsed genome was distinctly more hypermethylated compared to matched samples at diagnosis (3). In this study, $1147 \mathrm{CpG}$ sites corresponding to 905 genes were differentially hypermethylated at relapse. About a third of these genes exhibited concordant down-regulation of mRNA expression. Many of the known regulators of the Wnt pathway were hypermethylated and down regulated at relapse, including inhibitors of the $\beta$-catenin/TCF/LEF activity, as well as APC, WT1, cadherins (CDH1, CDH11), and SOX genes (SOX2, SOX8, SOX11, SOX21). Interestingly, PTPRO, a negative feedback inhibitor of the Wnt pathway that binds to Wnt and blocks its association with other receptors (21), was also hypermethylated and down regulated. This suggests that the Wnt pathway is over-activated at relapse and that aberrant DNA methylation may play a significant role in the activation of this pathway in relapsed ALL (3). Re-expression of these hypermethylated and down regulated genes was observed when leukemia cell lines were treated with decitabine. As well, enhanced chemosensitivity was observed when ALL cell lines and primary patient ALL samples were pretreated with decitabine followed by conventional cytotoxic chemotherapy (4).

In summary, DNA hypermethylation appears to play a significant role in the leukemogenesis of ALL and may be an important contributor toward relapse. As more studies interrogate the specific genes and or pathways influenced by hypermethylation in pediatric ALL, we will gain further insight toward strategies to therapeutically target these aberrant epigenetic changes and hopefully begin to make a greater impact in the treatment of this disease.

\section{HISTONE MODIFICATIONS}

Histones are small basic proteins involved in the spatial organization of DNA within the nucleus. The chromatin environment influences the "on-off" transcriptional states of a gene depending on the post-translational modifications of the histone proteins (22). Numerous covalent histone tail modifications, the most prominent being methylation and acetylation, can directly affect gene transcription (23). These modifications are highly specific for the particular amino acid position on the $\mathrm{N}$-terminal tails of the histones. For example, H3K4me3, H3K9 acetylation, H3K14 acetylation, and $\mathrm{H} 3 \mathrm{~K} 79 \mathrm{me} 2$ are associated with open chromatin structures and linked with transcriptional activation, while $\mathrm{H} 3 \mathrm{~K} 9 \mathrm{me} 3$ and $\mathrm{H} 3 \mathrm{~K} 27 \mathrm{me} 3$ are associated with closed chromatin, and hence transcriptional repression. These histone marks are regulated by the balance between competing enzymes such as the histone lysine methyltransferases (HKMTs) and histone demethylases (HKDMs), and the histone acetyltransferases (HATs) and histone deacetylases (HDACs) (24). Moreover, multiple histone modifications can be associated with critical regulatory elements of transcription such as enhancers, which can determine cell fate and differentiation $(23,25)$.

Mutations in epigenetic modifying genes are common in hematologic malignancies, including ALL (26-31). These mutations can result in a gain or loss of function of key genes known to regulate histone marks. Jaffe and colleagues, in pediatric ALL cell lines, have used global chromatin profiling, a tandem mass spectrometry strategy, to measure levels of histone modifications on bulk chromatin (29). In this work, a novel cluster of cell lines with a specific epigenetic signature was identified, characterized by increased dimethylation of histone $\mathrm{H} 3$ at lysine 36 (H3K36me2) and decreased unmodified H3K36. Approximately half of the cell lines in this cluster harbored the $t(4 ; 14)$ translocation, which is known to induce overexpression of NSD2 (24, $32,33)$. NSD2 is a member of the HKMTs that catalyze the conversion of unmodified H3K36 to mono- and dimethylated forms (28). Upon targeted sequencing in an extensive patient sample set, NSD2 mutations were found to be enriched in ETV6-RUNX1 and TCF3-PBX1 sub-types of pediatric B-ALL, while no mutations were identified in 30 adult ALL samples. These were gainof-function mutations and their overexpression led to a global increase in $\mathrm{H} 3 \mathrm{~K} 36 \mathrm{me}$, with concomitant decrease in H3K27me3. Similar results were reported by others (34), showing these mutations affect expression of a number of genes involved in normal lymphoid development.

Accumulating evidence suggests that histone modification is an important aspect of MLL-fusion mediated transformation and leukemogenesis $(35,36)$. It has been shown that wild type MLL SET domain is a methyltransferase, modifying histone $\mathrm{H} 3$ on lysine 4 (H3K4), and positively regulating gene expression of multiple Hox genes (37). In addition, MLL mediated transcriptional regulation involves recruitment of HAT, such as CBP (38) and MOF (39). Furthermore, DOT1L, a histone methyltransferase that methylates lysine 79 on histone H3 (H3K79), has been associated with multiple MLL-fusion partners such as AF9, AF10, AF17, and ENL (40-42), and has emerged as an attractive therapeutic target (36). Several groups have used small molecule inhibitors to demonstrate the feasibility of pharmacological inhibition of DOT1L enzymatic activity in preclinical models of MLL-rearranged leukemia (4345 ) and are now under clinical investigation in a phase I study for adults with advanced hematologic malignancies, including acute 
leukemia with rearrangement of the MLL gene (NCT01684150). One inhibitor in particular, EPZ-5676, has shown potent activity in its ability to selectively inhibit the DOT1L histone methyltransferase, resulting in cell death of acute leukemia cell lines harboring MLL translocations as well as complete tumor regression in a rat xenograft model of MLL-rearranged leukemia following continuous iv infusion of EPZ-5676 (45).

In order to identify novel mutations in relapsed ALL, Mullighan and colleagues performed targeted resequencing of 300 genes in 23 matched relapse-diagnosis B-ALL pairs (30). The authors identified novel mutations in CREBBP, a gene encoding the transcriptional coactivator CREB binding protein with HAT activity. The overall frequencies of these sequence and/or deletional mutations were $18.3 \%$ in relapse cases (30). However, particularly high incidences of somatic CREBBP alterations (63\%) were found in the high hyperdiploidy relapse cases. Of note, the majority of these mutations occurred in the HAT domain (27). Although less common, mutations in other important epigenetic regulators were also seen such as NCoR1 (Nuclear corepressor complex), EP300 (a paralog of CREBBP), EZH2 (histone methyltransferase gene), and CTCF (zinc finger protein involved in histone modifications) (30). Additionally, transcriptome sequencing has identified relapse-specific mutations in $C B X 3$ (encoding heterochromatin protein), PRMT2 (gene encoding protein arginine methyltransferase 2), and MIER3 (involved in chromatin binding); providing further evidence of aberrant epigenetic mechanisms that play a role at relapse (46).

Epigenetic alterations are not only restricted to B-ALL, but are a notable feature of T-ALL, particularly the aggressive subtype early T-cell precursor (ETP) ALL. Whole genome sequencing of 12 cases of ETP ALL identified mutations in genes encoding components of the polycomb repressor complex 2 (PRC2), including deletions and sequence mutations of EZH2, SUZ12, and EED (47). Loss of function mutations and deletions of EZH2 and SUZ12 genes have also been found in T-ALL, where authors implicate the tumor suppressor role of the PRC2 complex (48).

In addition to the discovery of somatic mutations in epigenetic machinery in ALL, mRNA expression of HDACs has been shown to be dysregulated. Higher mRNA expression of HDAC7 and HDAC9 in a study of 94 childhood ALL cases was shown to correlate with poor prognosis (49). Similarly, another group identified the correlation of HDAC4 overexpression with prednisone poor response, T-ALL phenotype, and a high initial WBC (50). Given the compelling evidence of HDAC's involvement in tumor development and progression, inhibitors of HDACs have emerged as an attractive therapeutic option in hematologic malignancies $(4,51)$. Through a connectivity map search (52) for agents, which could potentially reverse the characteristic gene expression signature specific for relapse $\operatorname{ALL}(3,53)$ and potentially endow chemosensitivity, vorinostat (HDACi) was identified as the most promising candidate (4). In fact, vorinostat not only modulated the gene expression signature characteristic of relapse in ALL cell lines and patient samples, but showed a synergistic effect when given sequentially with chemotherapy (4). The fact that vorinostat showed significant alteration of gene expression correlating with histone modifications, indicates that the perturbation of histone marks may have a key role in aberrant gene regulation at relapse. Bachmann and colleagues have reported glucocorticoid resistance associated with epigenetic silencing of the BIM gene in pediatric ALL and showed synergistic effect of vorinostat with dexamethasone in both in vitro and in vivo models (54). The potential importance of these changes is highlighted by the promising activity of several other drugs from the same class that target epigenetic alterations (55).

In summary, similar to the influence DNA hypermethylation has in pediatric ALL leukemogenesis, maintenance, and relapse, aberrant epigenetic changes involving histones have been associated with disease progression and relapse in ALL. With growing experience using $\mathrm{HDACi}$ in hematologic malignancies, including pediatric trials (NCT01483690, NCT01321346), the impact of these agents will become clearer as well as their role in future relapse and upfront ALL studies.

\section{MicroRNA ALTERATIONS}

MicroRNAs are a class of small endogenous single stranded non-coding ribonucleic acids (RNA) composed of roughly 22 nucleotides that are primarily involved in post-transcriptional gene regulation. miRNAs play a critical regulatory role in targeting mRNAs for cleavage or translational repression, with greater than 1,000 miRNAs currently identified in the human genome (56). MicroRNA genes are preferentially localized to CpG islands, which leads to the plausible mechanism that they can be controlled through aberrant epigenetic regulation (e.g., hypermethylation, histone modification) (57).

Altered expression of miRNAs has been implicated in leukemogenesis and appears to have the ability to influence critical growth regulatory pathways in ALL (58-61). An example of the functional impact miRNA can have in B-cell ALL was reported with the restoration of miR-196b expression, which led to significant down-regulation of c-myc and its effector genes fhTERT, $B c l$-2, and $A A T F$, suggesting a tumor suppressor function role for miR-196b (62). Some specific miRNAs that have been implicated in pediatric ALL include miRNA (miR) miR-34, miR-128, miR-142, and miR181 , all reported to be over expressed $(58,63,64)$ and miR-100 and miR-196b, both under expressed $(59,63)$. Schotte and colleagues investigated 397 miRNAs using qRT-PCR in 81 pediatric ALL cases in comparison to 17 normal CD34 ${ }^{+}$stem cell controls (65). Unique miRNA signatures were identified for various ALL sub-types including ETV6-RUNX1, MLL-rearranged, T-ALL, hyperdiploidy, and E2A-PBX1. Overall, expression of miR-143 and miR-140 were found to be 70- and 140-fold lower in the B-ALL samples compared to controls $\left(p_{\mathrm{FDR}}=0.0007\right.$ and $p_{\mathrm{FDR}}=0.001$, respectively). Hyperdiploid samples showed a clustering of high expression of miR-98, miR-222, miR-223, and miR-511 and the ETV6-RUNX1 cases had a 5- to 1700-fold increase expression in miR-99a, miR-100, miR-125b, and miR-383 compared to controls $\left(p_{\mathrm{FDR}}<0.001\right)$. Together these findings lend support for epigenetic alterations involving miRNAs in the leukemogenesis of some of the more common variants of pediatric ALL.

Aberrant miRNA expression has been implicated in leukemia drug resistance and lower event-free survival (EFS). Schotte and colleagues identified a lower expression of miR-454 (1.9fold lower) in leukemia blasts with $\mathrm{L}$-asparaginase resistance $\left(p_{\mathrm{FDR}}=0.017\right)$ and patient samples resistant to vincristine and 
daunorubicin were found to have over expression of miR99a, miR-100, and miR-125b (14- to 25-fold) $\left(p_{\text {FDR }} \leq 0.002\right.$ and $p_{\mathrm{FDR}}<0.05$, respectively) (65). In terms of EFS, six miRNAs (miR-33, -215, -369-5p, -496, -518d, and -599) were associated with worse survival (HR 1.3-1.52, 95\% CI 1.01-2.04; $0.003 \leq p \leq 0.046$ ) and another eight (miR-10a, -134, -214, -484, $-572,-580,-624$, and -627 ) with greater EFS (HR 0.59-0.82, 95\% CI $0.41-0.99,0.004 \leq p \leq 0.045)(65)$. The authors concluded that the miRNAs associated with a more favorable outcome likely had tumor suppressor activity through their signaling of apoptosis (miR-10a), inhibition of proliferation (miR-10a and miR-214), and oncogene SOX2 down-regulation (miR-134).

In a report of 18 matched-pair diagnosis and relapse $(n=8)$ or diagnosis and remission $(n=10)$ pediatric ALL samples, data was summarized for the most differentially expressed miRNAs (66). Down-regulation of miR-23a and miR-223 was observed at time of relapse compared to remission whereas miR130b, -181, and -708 were over expressed at relapse. Specifically, the expression of miR-708 was greater in relapse samples and lower in remission samples when compared to diagnosis whereas miR-223 was up-regulated in remission samples compared to diagnosis and confirmed with qRT-PCR. These two miRNAs at diagnosis along with miR-27a were shown to correlate significantly with 3-year relapse-free survival ( $p=0.0483,0.0079$, and 0.0024 , respectively) and thus could potentially be used as prognostic biomarkers for newly diagnosed patients. The functional impact these miRNAs had on gene expression was described as well with targets identified for $B M I 1$, transcription factor necessary for hematopoietic stem cell and leukemia stem cell self-renewal, in miR-27a and miR-128b as well as E2F1, master cell cycle regulator, a target of miR-223. The variations in miRNA expression that exist between diagnostic, remission, and relapse samples identified by Han and colleagues suggest that critical epigenetic mechanisms exist through these non-coding miRNAs that may assist in driving leukemogenesis and disease recurrence.

In an analysis of 353 diagnostic bone marrow samples from patients with ALL ( $<15$ years of age, $n=179)$, $65 \%$ had at least one of 13 previously identified miRNAs hypermethylated (67). These 13 miRNAs were found to be regulated by methylation and histone modification and associated with a closed chromatin conformation of $11 \mathrm{CpG}$ islands close to where the 13 miRNAs resided. The hypermethylation was associated with miRNA under expression but could be reversed with decitabine.

In summary, aberrant miRNA expression, particularly secondary to methylation, is a common finding in ALL. These data support that epigenetic modifications of specific miRNAs are associated with chemotherapy resistance and clinical outcomes. As these modifications can be secondary to DNA hypermethylation $(65,68-71)$, exposure to agents such as DNMTi could reverse the aberrant expression, normalize miRNA levels, and ultimately lead to improved clinical outcomes.

\section{CLINICAL TRIALS INVESTIGATING EPIGENETIC MODIFYING THERAPIES IN PEDIATRIC ALL}

The majority of clinical experience using epigenetic modifying agents in the treatment of acute leukemia has been in adults (72, 73). The Children's Oncology Group (COG) piloted a phase I study investigating decitabine $\left(10 \mathrm{mg} / \mathrm{m}^{2} /\right.$ day $\times 5$ days/week $\times 2$ weeks $)$ in children with relapsed/refractory acute leukemia that closed prematurely due to low patient accrual (NCT00042796, unpublished). No maximum tolerated dose (MTD) was identified and $5 / 15$ patients reported grade $3 / 4$ cytopenias (anemia, thrombocytopenia, and leukopenia) that were possibly related to the study drug.

Similar to the DNMTi, HDACi (e.g., vorinostat, panobinostat) have been studied in the treatment of acute leukemia, primarily as single agents and almost exclusively in adults $(74,75)$. The COG completed a phase I study investigating vorinostat in combination with 13 cis-retinoic acid in children with refractory/recurrent solid tumors and vorinostat alone for patients with refractory leukemia (76). Six patients with refractory leukemia were enrolled with 2 DLTs reported at the solid tumor MTD $\left(230 \mathrm{mg} / \mathrm{m}^{2} /\right.$ day $)$ including an elevated AST $(n=1)$, hyperbilirubinemia $(n=1)$, elevated GGT $(n=1)$, and hypokalemia $(n=1)$. As the solid tumor MTD for vorinostat did not appear tolerable for patients with hematologic malignancies, there was no further dose finding attempt in this study. Currently, there is a phase I study of panobinostat in children with refractory hematologic malignancies open through the therapeutic advances in childhood leukemia and lymphoma (TACL) Consortium (NCT01321346).

The first study incorporating a DNMTi and HDACi followed by chemotherapy for children and adults with relapsed/refractory ALL was recently completed (72). In this phase II trial, decitabine $\left(15 \mathrm{mg} / \mathrm{m}^{2} /\right.$ day $)$ and vorinostat $\left(230 \mathrm{mg} / \mathrm{m}^{2}\right.$ divided BID) were given over four consecutive days prior to re-induction chemotherapy (vincristine, prednisone, PEG-asparaginase, doxorubicin) (NCT00882206) (72). Thirteen eligible patients enrolled with a median age of 16 (range, 3-54) years. There was a single toxic death occurring on study attributed to the chemotherapy regimen, which included a grade five hemorrhage/bleeding $(n=1)$. A second patient experiencing grade five hypoxia/acute respiratory distress died on day 4 of study attributed to disease progression $(n=1)$. There were an additional 14 grade $3 / 4$ serious adverse events, which were at least possibly attributed to decitabine or vorinostat, the most common being fever with neutropenia $(n=2)$ and infection (blood) with neutropenia $(n=5)$. Results of the eight patients evaluable for response, identified a CR rate of 50\% $(n=4 / 8)(95 \%$ CI $15.7-84.3 \%)$ and an overall response rate $(\mathrm{CR}+\mathrm{PR})$ of $75 \%(n=6 / 8)(95 \%$ CI 34.9-96.8\%). As well, minimal residual disease (MRD) negativity by flow cytometry was observed in $4 / 8$ patients (50\%, CI: $15.7-84.3 \%$ ). Five of the eight patients who completed the study proceeded to allogeneic hematopoietic cell transplantation (four in second CR and one in third CR). Three patients succumbed to transplant related deaths without evidence of leukemia while the remaining two patients remain alive with no evidence of disease. Based on the results of this study, a pediatric trial for relapse/refractory ALL combining decitabine and vorinostat with re-induction chemotherapy is currently open through the TACL Consortium (NCT01483690; R21CA161688-01).

\section{SUMMARY}

Underlying epigenetic alterations in pediatric ALL are common events, which appear to be more common at relapse than 
diagnosis. Thus children with relapse ALL may be an ideal population for clinical trials incorporating epigenetic modifying agents aimed at reversing these aberrant signatures. Whether such trials will lead to improved clinical outcomes has yet to be determined but early findings in studies incorporating these agents have been encouraging.

In conclusion, leukemogenesis of pediatric ALL is heavily influenced by epigenetics, particularly DNA hypermethylation, histone modification, and alterations in miRNA expression. Epigenetic modifying agents such as DNMTi and HDACi as well as newer therapies (e.g., histone methyltransferase inhibitors) are now being incorporated into early phase clinical trials for relapse leukemia. As more trials for children with relapse ALL, incorporating epigenetic therapies into standard and/or novel salvage regimens, are developed and completed, we will have a better understanding as to which patients might benefit the most using this approach and ultimately where these agents may be best served in treating pediatric ALL.

\section{REFERENCES}

1. Garcia-Manero G, Yang H, Kuang SQ, O’Brien S, Thomas D, Kantarjian H. Epigenetics of acute lymphocytic leukemia. Semin Hematol (2009) 46:24-32. doi:10.1053/j.seminhematol.2008.09.008

2. Sandoval J, Esteller M. Cancer epigenomics: beyond genomics. Curr Opin Genet $\operatorname{Dev}$ (2012) 22:50-5. doi:10.1016/j.gde.2012.02.008

3. Hogan LE, Meyer JA, Yang J, Wang J, Wong N, Yang W, et al. Integrated genomic analysis of relapsed childhood acute lymphoblastic leukemia reveals therapeutic strategies. Blood (2011) 118:5218-26. doi:10.1182/blood-2011-04-345595

4. Bhatla T, Wang J, Morrison DJ, Raetz EA, Burke MJ, Brown P, et al. Epigenetic reprogramming reverses the relapse-specific gene expression signature and restores chemosensitivity in childhood B-lymphoblastic leukemia. Blood (2012) 119:5201-10. doi:10.1182/blood-2012-01-401687

5. Garcia-Manero G, Bueso-Ramos C, Daniel J, Williamson J, Kantarjian HM, Issa JP. DNA methylation patterns at relapse in adult acute lymphocytic leukemia. Clin Cancer Res (2002) 8:1897-903.

6. Gaynon PS. Childhood acute lymphoblastic leukaemia and relapse. Br J Haematol (2005) 131:579-87. doi:10.1111/j.1365-2141.2005.05773.x

7. Baylin SB, Herman JG. DNA hypermethylation in tumorigenesis: epigenetics joins genetics. Trends Genet (2000) 16:168-74. doi:10.1016/S0168-9525(99) 01971-X

8. Costello JF, Plass C. Methylation matters. J Med Genet (2001) 38:285-303. doi:10.1136/jmg.38.5.285

9. Roman-Gomez J, Castillejo JA, Jimenez A, Barrios M, Heiniger A, Torres A. The role of DNA hypermethylation in the pathogenesis and prognosis of acute lymphoblastic leukemia. Leuk Lymphoma (2003) 44:1855-64. doi:10.1080/ 1042819031000116689

10. Figueroa ME, Chen SC, Andersson AK, Phillips LA, LiY, Sotzen J, et al. Integrated genetic and epigenetic analysis of childhood acute lymphoblastic leukemia. $J$ Clin Invest (2013) 123:3099-111. doi:10.1172/JCI66203

11. Chatterton Z, Morenos L, Mechinaud F, Ashley DM, Craig JM, Sexton-Oates A, et al. Epigenetic deregulation in pediatric acute lymphoblastic leukemia. Epigenetics (2014) 9:3. doi:10.4161/epi.27585

12. Nordlund J, Backlin CL, Wahlberg P, Busche S, Berglund EC, Eloranta ML, et al. Genome-wide signatures of differential DNA methylation in pediatric acute lymphoblastic leukemia. Genome Biol (2013) 14. doi:10.1186/gb-2013-14-9r105

13. Ernst J, Kheradpour P, Mikkelsen TS, Shoresh N, Ward LD, Epstein CB, et al. Mapping and analysis of chromatin state dynamics in nine human cell types. Nature (2011) 473:43-9. doi:10.1038/nature09906

14. Deneberg S, Guardiola P, Lennartsson A, Qu Y, Gaidzik V, Blanchet O, et al. Prognostic DNA methylation patterns in cytogenetically normal acute myeloid leukemia are predefined by stem cell chromatin marks. Blood (2011) 118:5573-82. doi:10.1182/blood-2011-01-332353

15. Ammerpohl O, Haake A, Pellissery S, Giefing M, Richter J, Balint B, et al. Array-based DNA methylation analysis in classical Hodgkin lymphoma reveals new insights into the mechanisms underlying silencing of B cell-specific genes. Leukemia (2012) 26:185-8. doi:10.1038/leu.2011.194

16. Stumpel DJ, Schotte D, Lange-Turenhout EA, Schneider P, Seslija L, de Menezes RX, et al. Hypermethylation of specific microRNA genes in MLL-rearranged infant acute lymphoblastic leukemia: major matters at a micro scale. Leukemia (2011) 25:429-39. doi:10.1038/leu.2010.282

17. Schafer E, Irizarry R, Negi S, McIntyre E, Small D, Figueroa ME, et al. Promoter hypermethylation in MLL-r infant acute lymphoblastic leukemia: biology and therapeutic targeting. Blood (2010) 115:4798-809. doi:10.1182/blood-2009-09243634

18. Nishi M, Eguchi-Ishimae M, Wu Z, Gao W, Iwabuki H, Kawakami S, et al. Suppression of the let-7b microRNA pathway by DNA hypermethylation in infant acute lymphoblastic leukemia with MLL gene rearrangements. Leukemia (2013) 27:389-97. doi:10.1038/leu.2012.242

19. Stumpel DJ, Schneider P, van Roon EH, Boer JM, de Lorenzo P, Valsecchi MG, et al. Specific promoter methylation identifies different subgroups of MLLrearranged infant acute lymphoblastic leukemia, influences clinical outcome, and provides therapeutic options. Blood (2009) 114:5490-8. doi:10.1182/blood2009-06-227660

20. Klumper E, Pieters R, Veerman AJ, Huismans DR, Loonen AH, Hahlen K, et al. In vitro cellular drug resistance in children with relapsed/refractory acute lymphoblastic leukemia. Blood (1995) 86:3861-8.

21. Kim M, Kim H, Jho E-H. Identification of ptpro as a novel target gene of Wnt signaling and its potential role as a receptor for Wnt. FEBS Lett (2010) 584:3923-8. doi:10.1016/j.febslet.2010.08.034

22. Jenuwein T, Allis CD. Translating the histone code. Science (2001) 293:1074-80. doi:10.1126/science.1063127

23. Wang Z, Zang C, Rosenfeld JA, Schones DE, Barski A, Cuddapah S, et al. Combinatorial patterns of histone acetylations and methylations in the human genome. Nat Genet (2008) 40:897-903. doi:10.1038/ng.154

24. Rea S, Eisenhaber F, O'Carroll D, Strahl BD, Sun ZW, Schmid M, et al. Regulation of chromatin structure by site-specific histone $\mathrm{H} 3$ methyltransferases. Nature (2000) 406:593-9. doi:10.1038/35020506

25. Rada-Iglesias A, Bajpai R, Swigut T, Brugmann SA, Flynn RA, Wysocka J. A unique chromatin signature uncovers early developmental enhancers in humans. Nature (2011) 470:279-83. doi:10.1038/nature09692

26. Papaemmanuil E, Gerstung M, Malcovati L, Tauro S, Gundem G, Van Loo P, et al. Myeloid disorders working group of the International Cancer Genome, clinical and biological implications of driver mutations in myelodysplastic syndromes. Blood (2013) 122:3616-27. doi:10.1182/blood-2013-08-518886

27. Inthal A, Zeitlhofer P, Zeginigg M, Morak M, Grausenburger R, Fronkova $\mathrm{E}$, et al. mutations prevail in relapse cases of high hyperdiploid childhood acute lymphoblastic leukemia. Leukemia (2012) 26:1797-803. doi:10.1038/leu. 2012.60

28. Kuo AJ, Cheung P, Chen K, Zee BM, Kioi M, Lauring J, et al. NSD2 links dimethylation of histone $\mathrm{H} 3$ at lysine 36 to oncogenic programming. Mol Cell (2011) 44:609-20. doi:10.1016/j.molcel.2011.08.042

29. Jaffe JD, Wang Y, Chan HM, Zhang J, Huether R, Kryukov GV, et al. Global chromatin profiling reveals NSD2 mutations in pediatric acute lymphoblastic leukemia. Nat Genet (2013) 45:1386-91. doi:10.1038/ng.2777

30. Mullighan CG, Zhang J, Kasper LH, Lerach S, Payne-Turner D, Phillips LA, et al. CREBBP mutations in relapsed acute lymphoblastic leukaemia. Nature (2011) 471:235-9. doi:10.1038/nature09727

31. Khan SN, Jankowska AM, Mahfouz R, Dunbar AJ, Sugimoto Y, Hosono N, et al. Multiple mechanisms deregulate EZH2 and histone H3 lysine 27 epigenetic changes in myeloid malignancies. Leukemia (2013) 27:1301-9. doi:10.1038/leu. 2013.80

32. Malgeri U, Baldini L, Perfetti V, Fabris S, Vignarelli MC, Colombo G, et al. Detection of $\mathrm{t}(4 ; 14)(\mathrm{p} 16.3 ; \mathrm{q} 32)$ chromosomal translocation in multiple myeloma by reverse transcription-polymerase chain reaction analysis of IGH-MMSET fusion transcripts. Cancer Res (2000) 60:4058-61.

33. Chesi M, Nardini E, Lim RS, Smith KD, Kuehl WM, Bergsagel PL. The $\mathrm{t}(4 ; 14)$ translocation in myeloma dysregulates both FGFR3 and a novel gene, MMSET, resulting in IgH/MMSET hybrid transcripts. Blood (1998) 92: 3025-34.

34. Oyer JA, Huang X, Zheng Y, Shim J, Ezponda T, Carpenter Z, et al. Point mutation E1099K in MMSET/NSD2 enhances its methyltranferase activity and leads to altered global chromatin methylation in lymphoid malignancies. Leukemia (2014) 28:198-201. doi:10.1038/leu.2013.204 
35. Krivtsov AV, Feng Z, Lemieux ME, Faber J, Vempati S, Sinha AU, et al. H3K79 methylation profiles define murine and human MLL-AF4 leukemias. Cancer Cell (2008) 14:355-68. doi:10.1016/j.ccr.2008.10.001

36. Bernt KM, Armstrong SA. Targeting epigenetic programs in MLL-rearranged leukemias. Hematology Am Soc Hematol Educ Program (2011) 2011:354-60. doi:10.1182/asheducation-2011.1.354

37. Milne TA, Briggs SD, Brock HW, Martin ME, Gibbs D, Allis CD, et al. SET domain methyltransferase activity to Hox gene promoters. Mol Cell (2002) 10:1107-17. doi:10.1016/S1097-2765(02)00741-4

38. Ernst P, Wang J, Huang M, Goodman RH, Korsmeyer SJ. MLL and CREB bind cooperatively to the nuclear coactivator CREB-binding protein. Mol Cell Biol (2001) 21:2249-58. doi:10.1128/MCB.21.7.2249-2258.2001

39. Dou Y, Milne TA, Tackett AJ, Smith ER, Fukuda A, Wysocka J, et al. Physical association and coordinate function of the H3 K4 methyltransferase MLL1 and the H4 K16 acetyltransferase MOF. Cell (2005) 121:873-85. doi:10.1016/j.cell. 2005.04.031

40. Okada Y, Feng Q, Lin Y, Jiang Q, Li Y, Coffield VM, et al. hDOT1L links histone methylation to leukemogenesis. Cell (2005) 121:167-78. doi:10.1016/j.cell.2005. 05.021

41. Mueller D, Bach C, Zeisig D, Garcia-Cuellar M-P, Monroe S, Sreekumar A, et al. A role for the MLL fusion partner ENL in transcriptional elongation and chromatin modification. Blood (2007) 110:4445-54. doi:10.1182/blood-2007-05090514

42. Zhang W, Xia X, Reisenauer MR, Hemenway CS, Kone BC. Dotla-AF9 complex mediates histone $\mathrm{H} 3$ Lys-79 hypermethylation and repression of ENaC $\alpha$ in an aldosterone-sensitive manner. J Biol Chem (2006) 281:18059-68. doi:10.1074/ jbc.M601903200

43. Daigle SR, Olhava EJ, Therkelsen CA, Majer CR, Sneeringer CJ, Song J,et al. Selective killing of mixed lineage leukemia cells by a potent small-molecule DOT1L inhibitor. Cancer Cell (2011) 20:53-65. doi:10.1016/ j.ccr.2011.06.009

44. Chen L, Deshpande AJ, Banka D, Bernt KM, Dias S, Buske C, et al. Abrogation of MLL-AF10 and CALM-AF10-mediated transformation through genetic inactivation or pharmacological inhibition of the H3K79 methyltransferase Dotll. Leukemia (2013) 27:813-22. doi:10.1038/leu.2012.327

45. Daigle SR, Olhava EJ, Therkelsen CA, Basavapathruni A, Jin L, Boriack-Sjodin $\mathrm{PA}$, et al. Potent inhibition of DOT1L as treatment of MLL-fusion leukemia. Blood (2013) 122:1017-25. doi:10.1182/blood-2013-04-497644

46. Meyer JA, Wang J, Hogan LE, Yang JJ, Dandekar S, Patel JP, et al. Relapse-specific mutations in NT5C2 in childhood acute lymphoblastic leukemia. Nat Genet (2013) 45:290-4. doi:10.1038/ng.2558

47. Zhang J, Ding L, Holmfeldt L, Wu G, Heatley SL, Payne-Turner D, et al. The genetic basis of early T-cell precursor acute lymphoblastic leukaemia. Nature (2012) 481:157-63. doi:10.1038/nature 10725

48. Ntziachristos P, Tsirigos A, Van Vlierberghe P, Nedjic J, Trimarchi T, Flaherty MS, et al. Genetic inactivation of the polycomb repressive complex 2 in T cell acute lymphoblastic leukemia. Nat Med (2012) 18:298-301. doi:10.1038/nm. 2651

49. Moreno DA, Scrideli CA, Cortez MA, de Paula Queiroz R, Valera ET, Yunes JA, et al. Differential expression of HDAC3, HDAC7 and HDAC9 is associated with prognosis and survival in childhood acute lymphoblastic leukaemia. $\mathrm{Br} \mathrm{J}$ Haematol (2010) 150:665-73. doi:10.1111/j.1365-2141.2010.08301.x

50. Gruhn B, Naumann T, Gruner D, Walther M, Wittig S, Becker S, et al. The expression of histone deacetylase 4 is associated with prednisone poor-response in childhood acute lymphoblastic leukemia. Leuk Res (2013) 37:1200-7. doi:10. 1016/j.leukres.2013.07.016

51. Lane AA, Chabner BA. Histone deacetylase inhibitors in cancer therapy. J Clin Oncol (2009) 27:5459-68. doi:10.1200/JCO.2009.22.1291

52. Lamb J, Crawford ED, Peck D, Modell JW, Blat IC, Wrobel MJ, et al. The Connectivity Map: using gene-expression signatures to connect small molecules, genes, and disease. Science (2006) 313:1929-35. doi:10.1126/science. 1132939

53. Bhojwani D, Kang H, Moskowitz NP, Min DJ, Lee H, Potter JW, et al. Biologic pathways associated with relapse in childhood acute lymphoblastic leukemia: a Children's Oncology Group study. Blood (2006) 108:711-7. doi:10.1182/blood2006-02-002824

54. Bachmann PS, Piazza RG, Janes ME, Wong NC, Davies C, Mogavero A, et al. Epigenetic silencing of BIM in glucocorticoid poor-responsive pediatric acute lymphoblastic leukemia, and its reversal by histone deacetylase inhibition. Blood (2010) 116:3013-22. doi:10.1182/blood-2010-05-284968

55. Jones PA, Baylin SB. The epigenomics of cancer. Cell (2007) 128:683-92. doi:10.1016/j.cell.2007.01.029

56. de Oliveira JC, Brassesco MS, Scrideli CA, Tone LG, Narendran A. MicroRNA expression and activity in pediatric acute lymphoblastic leukemia (ALL). Pediatr Blood Cancer (2012) 59:599-604. doi:10.1002/pbc.24167

57. Weber B, Stresemann C, Brueckner B, Lyko F. Methylation of human microRNA genes in normal and neoplastic cells. Cell Cycle (2007) 6:1001-5. doi:10.4161/ cc.6.9.4209

58. Ju X, Li D, Shi Q, Hou H, Sun N, Shen B. Differential microRNA expression in childhood B-cell precursor acute lymphoblastic leukemia. Pediatr Hematol Oncol (2009) 26:1-10. doi:10.1080/08880010802378338

59. Schotte D, Chau JC, Sylvester G, Liu G, Chen C, van der Velden VH, et al. Identification of new microRNA genes and aberrant microRNA profiles in childhood acute lymphoblastic leukemia. Leukemia (2009) 23:313-22. doi:10.1038/ leu. 2008.286

60. Mi S, Lu J, Sun M, Li Z, Zhang H, Neilly MB, et al. MicroRNA expression signatures accurately discriminate acute lymphoblastic leukemia from acute myeloid leukemia. Proc Natl Acad Sci USA (2007) 104:19971-6. doi:10.1073/ pnas.0709313104

61. Zanette DL, Rivadavia F, Molfetta GA, Barbuzano FG, Proto-Siqueira R, Silva-Jr WA, et al. miRNA expression profiles in chronic lymphocytic and acute lymphocytic leukemia. Braz J Med Biol Res (2007) 40:1435-40. doi:10.1590/S0100879X2007001100003

62. Bhatia S, Kaul D, Varma N. Potential tumor suppressive function of miR$196 \mathrm{~b}$ in B-cell lineage acute lymphoblastic leukemia. Mol Cell Biochem (2010) 340:97-106. doi:10.1007/s11010-010-0406-9

63. de Oliveira JC, Scrideli CA, Brassesco MS, Morales AG, Pezuk JA, Queiroz Rde P, et al. Differential miRNA expression in childhood acute lymphoblastic leukemia and association with clinical and biological features. Leuk Res (2012) 36:293-8. doi:10.1016/j.leukres.2011.10.005

64. Zhang H, Luo XQ, Zhang P, Huang LB, Zheng YS, Wu J, et al. MicroRNA patterns associated with clinical prognostic parameters and CNS relapse prediction in pediatric acute leukemia. PLoS One (2009) 4:e7826. doi:10.1371/journal.pone. 0007826

65. Schotte D, De Menezes RX, Akbari Moqadam F, Khankahdani LM, LangeTurenhout E, Chen C, et al. MicroRNA characterize genetic diversity and drug resistance in pediatric acute lymphoblastic leukemia. Haematologica (2011) 96:703-11. doi:10.3324/haematol.2010.026138

66. Han BW, Feng DD, Li ZG, Luo XQ, Zhang H, Li XJ, et al. A set of miRNAs that involve in the pathways of drug resistance and leukemic stem-cell differentiation is associated with the risk of relapse and glucocorticoid response in childhood ALL. Hum Mol Genet (2011) 20:4903-15. doi:10.1093/hmg/ddr428

67. Agirre X, Martinez-Climent JA, Odero MD, Prosper F. Epigenetic regulation of miRNA genes in acute leukemia. Leukemia (2012) 26:395-403. doi:10.1038/leu. 2011.344

68. Chen BF, Gu S, Suen YK, Li L, Chan WY. microRNA-199a-3p, DNMT3A, and aberrant DNA methylation in testicular cancer. Epigenetics (2013) 9:119-28. doi:10.4161/epi.25799

69. Fiaschetti G, Abela L, Nonoguchi N, Dubuc AM, Remke M, Boro A, et al. Epigenetic silencing of miRNA-9 is associated with HES1 oncogenic activity and poor prognosis of medulloblastoma. Br J Cancer (2014) 110:636-47. doi:10.1038/bjc. 2013.764

70. Gu S, Cheung HH, Lee TL, Lu G, Poon WS, Chan WY. Molecular mechanisms of regulation and action of microRNA-199a in testicular germ cell tumor and glioblastomas. PLoS One (2013) 8:e83980. doi:10.1371/journal.pone. 0083980

71. Roman-Gomez J, Agirre X, Jimenez-Velasco A, Arqueros V, Vilas-Zornoza A, Rodriguez-Otero $\mathrm{P}$, et al. Epigenetic regulation of microRNAs in acute lymphoblastic leukemia. J Clin Oncol (2009) 27:1316-22. doi:10.1200/JCO.2008.19. 3441

72. Burke MJ, Lamba J, Weigel B, Bachanova V, Verneris MR, Miller JS. A phase II trial of decitabine and vorinostat in combination with chemotherapy for relapsed/refractory acute lymphoblastic leukemia. ASH Annual Meeting Abstracts (2012) 120:4307.

73. Garcia-Manero G, Thomas D, Rytting M, Zweidler-McKay P, Estrov Z, Brown DL, et al. Phase I study of 5-aza-2'-deoxycitidine, alone or in combination with 
hyper-CVAD, in relapsed or refractory acute lymphocytic leukemia (ALL). ASH Annual Meeting Abstracts (2007) 110:2826.

74. Giles F, Fischer T, Cortes J, Garcia-Manero G, Beck J, Ravandi F, et al. A phase I study of intravenous LBH589, a novel cinnamic hydroxamic acid analogue histone deacetylase inhibitor, in patients with refractory hematologic malignancies. Clin Cancer Res (2006) 12:4628-35. doi:10.1158/1078-0432.CCR-06-0511

75. Garcia-Manero G, Yang H, Bueso-Ramos C, Ferrajoli A, Cortes J, Wierda WG, et al. Phase 1 study of the histone deacetylase inhibitor vorinostat (suberoylanilide hydroxamic acid [SAHA]) in patients with advanced leukemias and myelodysplastic syndromes. Blood (2008) 111:1060-6. doi:10.1182/blood2007-06-098061

76. Fouladi M, Park JR, Stewart CF, Gilbertson RJ, Schaiquevich P, Sun J, et al. Pediatric phase I trial and pharmacokinetic study of vorinostat: a Children's Oncology Group phase I consortium report. J Clin Oncol (2010) 28:3623-9. doi:10.1200/JCO.2009.25.9119
Conflict of Interest Statement: The authors declare that the research was conducted in the absence of any commercial or financial relationships that could be construed as a potential conflict of interest.

Received: 30 January 2014; accepted: 29 April 2014; published online: 14 May 2014. Citation: Burke MJ and Bhatla T (2014) Epigenetic modifications in pediatric acute lymphoblastic leukemia. Front. Pediatr. 2:42. doi: 10.3389/fped.2014.00042

This article was submitted to Pediatric Oncology, a section of the journal Frontiers in Pediatrics.

Copyright $\odot 2014$ Burke and Bhatla. This is an open-access article distributed under the terms of the Creative Commons Attribution License (CC BY). The use, distribution or reproduction in other forums is permitted, provided the original author(s) or licensor are credited and that the original publication in this journal is cited, in accordance with accepted academic practice. No use, distribution or reproduction is permitted which does not comply with these terms. 